Part of Journal of Research of the National Bureau of Standards, Volume 23, October 1939

\title{
REFLUX REGULATOR AND HEAD FOR LABORATORY RECTIFYING COLUMNS ${ }^{1}$
}

\author{
By Frederick D. Rossini and Augustus R. Glasgow, Jr. ${ }^{2}$
}

\section{ABSTRACT}

A reflux regulator and head for laboratory rectifying columns is described that (a) has a nonlubricated glass valve, (b) utilizes a minimum of height above the rectifying section of the column, (c) provides for a substantially constant rate of removal of distillate for each setting of the valve, (d) provides for estimation of the "throughput" and the reflux ratio, (e) provides space for a thermometric device, and (f) has a flexible metal partition for permitting distillation at pressures below or above the prevailing atmospheric pressure.

\section{CONTENTS}

I. Introduction

II. Description of apparatus

III. Discussion of apparatus...

IV. References_._.

\section{INTRODUCTION}

A number of reflux regulators and heads for laboratory rectifying columns have been described in the literature, and their important features for various services have been discussed [ 1 to 15,17 to 22]. ${ }^{3}$ Although each of the existing reflux regulators has advantages in some particular respects, none appears to fulfill all the special requirements arising in connection with the present work of the American Petroleum Institute Research Project 6 at the National Bureau of Standards. These special requirements for the reflux regulator and head are that the device should (a) have a nonlubricated glass valve; (b) utilize a minimum of height above the column proper and permit the use of as long a rectifying section as possible; (c) provide for a substantially constant rate of removal of distillate from the column for a given setting of the valve (when the material being distilled is in one phase and is not too inhomogeneous with respect to density and viscosity); (d) provide for a rate of removal of distillate that is controllable within fairly small steps from zero to 100 percent of the material returning to the column from the condenser; (e) have, for distillation at pressures below or above the prevailing atmospheric pressure, a closed boundary between the distillation pressure and the atmospheric pressure that is made by a flexible partition rather than by a packing gland; (f) provide for convenient estimation of the rate of removal of distillate; $(\mathrm{g})$ provide for convenient estimation of the throughput of

1 This investigation is part of the work of Research Project 6 of the American Petroleum Institute, from whose research fund financial assistance has been received.

2 Research Associate at the National Bureau of Standards, representing the American Petroleum Institute.

8 Figures in brackets indicate the literature references at the end of this paper. 
the column; and (h) provide a suitable space for a small thermometric device (thermoelement or resistance thermometer).

This paper describes a reflux regulator and head that possesses the foregoing properties.

\section{DESCRIPTION OF APPARATUS}

Figure 1 gives an assembly drawing of the reflux regulator and head. $A$ marks the connection to the rectifying section of the column. $B$ is a U-tube, with drop counter on the return end, for returning the con-

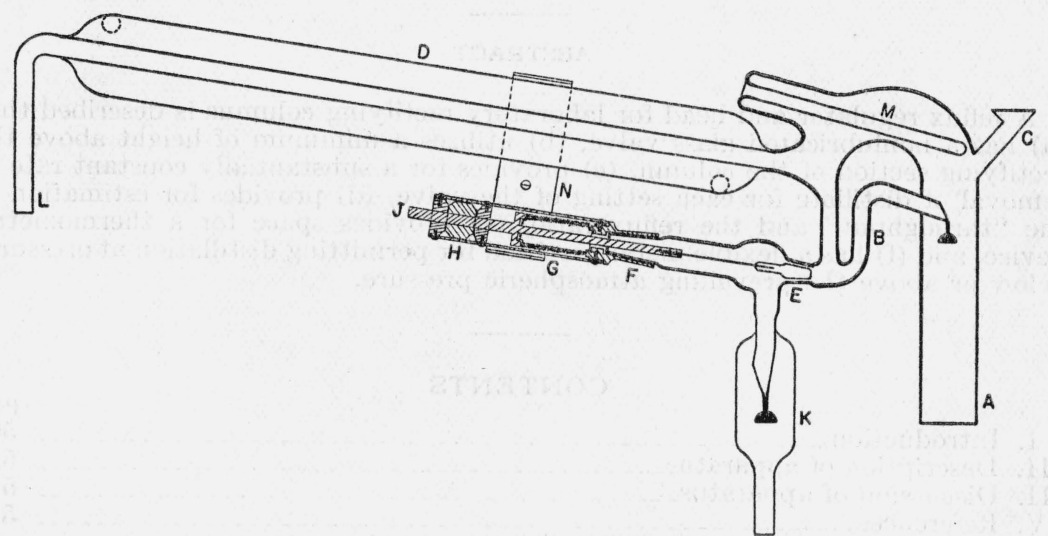

Figdre 1.-Assembly of reflux regulator and head.

densate to the rectifying section. $C$ is a temporary funnel (later sealed off) for introducing additional packing into the rectifying section after the seal at $A$ is made (if the rectifying section is a packed one). $D$ is a condenser. $E$ is a glass valve, consisting of a carefully ground plug and socket, which may be adjusted to remove any fraction of the overhead condensate. $F$ is a metal-to-glass tapered joint. $G$ is a metallic bellows (inside the metal housing). $H$ is a knurled nut that moves the metal stem, $J$, longitudinally, without any rotary motion, to adjust the opening at the glass valve, $E . \quad K$ is a drop counter with connection to the receiver for the distillate. $L$ is a connection to the atmosphere or controlled pressure or vacuum system. $M$ is a tube for receiving a thermoelement or small resistance thermometer. $N$ is a metal strap, covered on the inner side with asbestos paper, that is placed around the glass condenser and the metal tube, with the ends bolted together between the two, to provide additional support for the metal tube.

The metal-to-glass tapered joint is made with ordinary solder, according to the method described by Meyers [16], and provides a vacuum-tight and mechanically strong connection. It is necessary that a higher-melting solder be used in sealing the ends of the metallic bellows to the metal valve stem and the metal taper, in order that these two seals will remain vacuum-tight when the metal-to-glass connection at $F$ is made with ordinary solder. 
Figure 2 gives a detailed drawing of the glass part of the apparatus, and figure 3 that of the metal housing and control for the glass valve. These drawings are self-explanatory. ${ }^{4}$

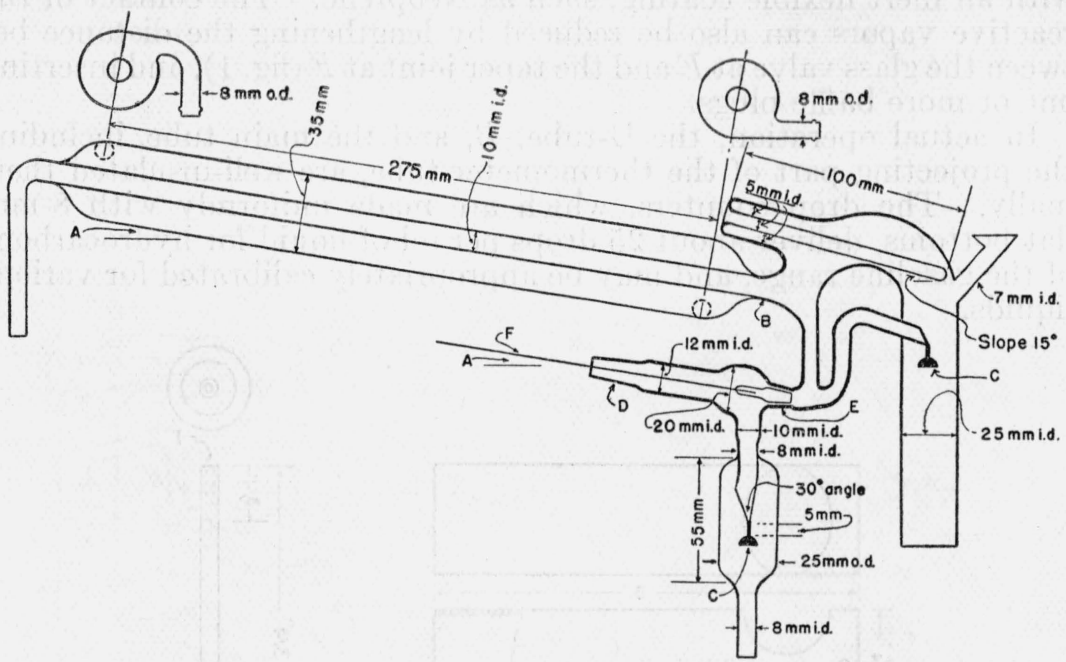

Figure 2.-Details of the glass part of the apparatus.

The letters have the following significance: $A$, slope $81 / 2^{\circ} ; B$, gradual slope, no pocket; $C$, drop counter, made hemispherical, ground flat on bottom, $8 \mathrm{~mm}$ in diameter; $D$, standard taper, male, No. 12/20, male, large end $12 \mathrm{~mm}$, small end $10 \mathrm{~mm}$, length $20 \mathrm{~mm}$, ground for high vacuum, to fit metal female taper shown in Figure $3 ; E$, taper, No. $6 / 10$, male and female, large end $6 \mathrm{~mm}$, small end $4 \mathrm{~mm}$, length $10 \mathrm{~mm}$, ground for high vacuum; $F$, tungsten wire, No. $18 \mathrm{AWG}$, hard soldered to the brass stem on one end and sealed into the ground-glass stopper on the other, length such that when the metal-to-glass joint ( $F$ in Figure 1$)$ is made and the ground-glass stopper is closed in its seat, the sylphon bellows will be slightly compressed to make the distance $A$ on the bellows in Figure 3 equal to $32 \mathrm{~mm}$. The wall thickness of the glass should be extra heavy $\left(1 \frac{1}{\mathrm{a}} \mathrm{mm}\right)$ where indicated by heavy lines, particularly at the base of the glass valve.

\section{DISCUSSION OF APPARATUS}

If the rectifying column is to be used entirely for distillation at atmospheric pressure, the metal housing and valve control shown in figures 1 and 3 may be replaced by the simpler one shown in figure 4, which is the same as the former with the exception that it is without the bellows. When the simpler metal control is used, it is desirable to increase the length of glass tubing between the valve at $E$ and the taper at $F$, and possibly insert baffle plugs, in order to prevent significant loss of distillate by vaporization through the metal control.

If a mercury-in-glass thermometer is to be used, the thermometer tube, $M$, should be increased in length to provide the needed greater immersion. This can be accomplished by increasing the horizontal distance between the vertical rectifying section and the near end of the condenser.

\footnotetext{
4 Because the dimensions of the bellows are more simply expressed in inches, the dimensions of the metal parts in figures 3 and 4 are all given in inches, except for the metal tapers, the dimensions of which are given in millimeters to conform with the units used for the glass apparatus.
} 
To provide for the distillation of material whose vapors may react with the metal parts of the valve control, the exposed metal surfaces, especially the inner surface of the metallic bellows, can be covered with an inert flexible coating, such as Neoprene. The contact of the reactive vapors can also be reduced by lengthening the distance between the glass valve at $E$ and the taper joint at $F$ (fig. 1), and inserting one or more baffle plugs.

In actual operation, the U-tube, $B$, and the main tube, including the projecting part of the thermometer tube, are well-insulated thermally. The drop counters, which are made uniformly with $8-\mathrm{mm}$ flat bottoms, deliver about 25 drops per $\mathrm{ml}$ of liquid for hydrocarbons of the gasoline range, and may be appropriately calibrated for various liquids.
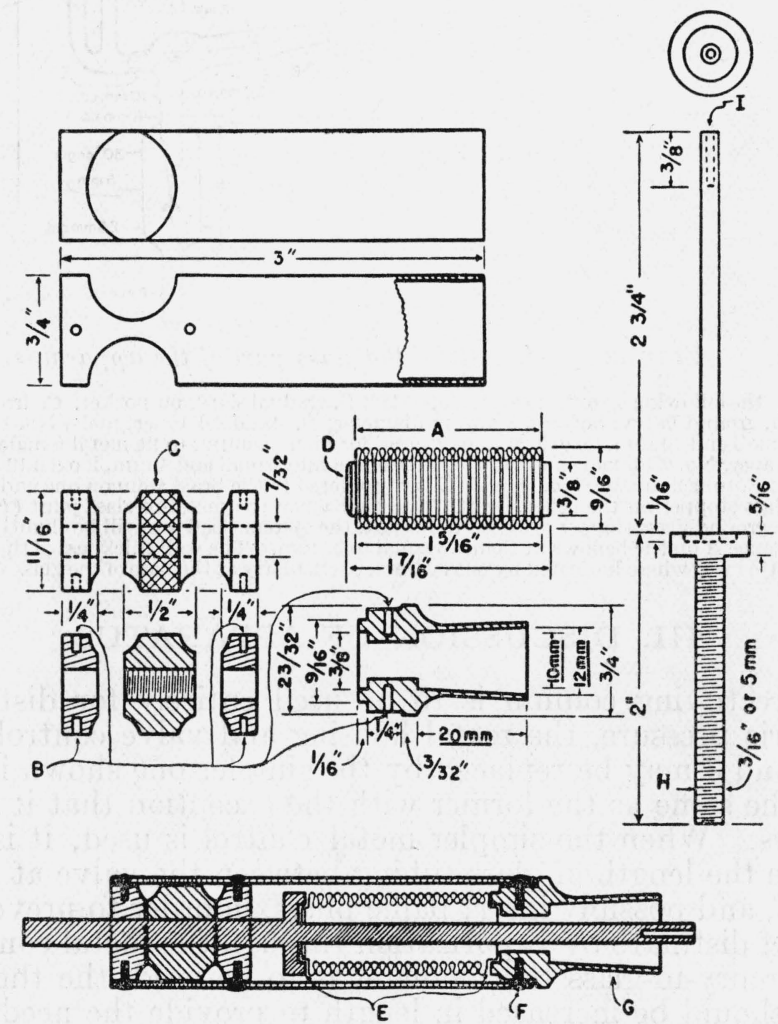

FIgURE 3.-Details of the metal housing and control.

The letters have the following significance: $A$, see $F$ in legend of Figure $2 ; B$, tapped for small screws, as $1.4 \mathrm{~mm}$ Loewenherz; $C$, surface of nut is knurled; $D$, sylphon bellows; $E$, ends of the sylphon bellows are hard-soldered to the two brass pieces, to hold high vacuum; $F$, brass tube is held in place by a close-fitting joint, fastened with screws as shown; $G$, standard taper, No. 12/20, female, large end $12 \mathrm{~mm}$, small end $10 \mathrm{~mm}$, length $20 \mathrm{~mm} ; H$, main shaft and knurled nut to be threaded about 50 threads per inch; $I$, hole $3 / 64$ inch in diameter.

For a given setting of the glass valve, the constancy of flow of liquid through it is indicated by the following figures from observations taken at intervals of about $1 / 2 \mathrm{hr}$ over an unselected $13-\mathrm{hr}$ period, which gave the time in seconds for the fall of 10 drops: average of 27 observations, $61.8 \mathrm{sec}$; maximum deviation, $3.2 \mathrm{sec}$; average deviation, $1.1 \mathrm{sec}$. 
In very little time, the valve can be set for any given rate of removal of distillate within about 10 percent, the smallest rate (other than zero) being of the order of $0.03 \mathrm{ml}$ liquid per minute and the largest rate, with the valve wide open, being the entire overhead condensate.
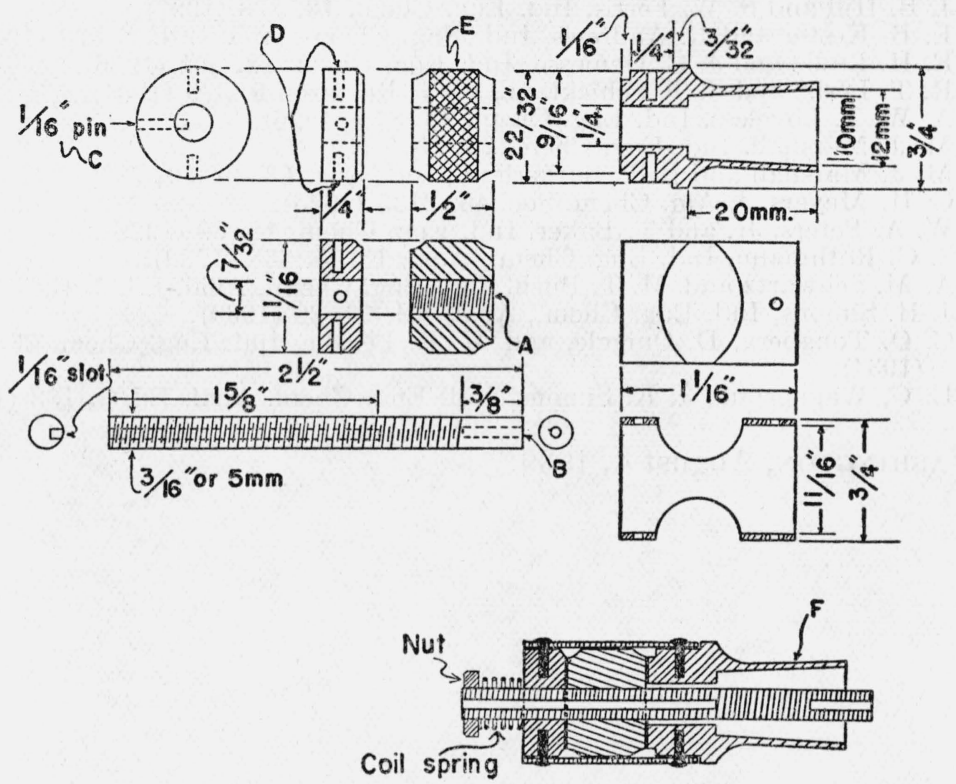

Figure 4.- Simple metal control for glass valve.

The letters have the following significance: $A$, nut threaded to fit the main shaft, about 50 threads per inch; $B$, hole 364 inch in diameter; $C$, slot to keep shaft from turning; $D$, holes tapped for small screws as shown; $E$, surface of nut is knurled; $F$, standard taper, female, No. $12 / 20$, large end $12 \mathrm{~mm}$, small end $10 \mathrm{~mm}$, length $20 \mathrm{~mm}$, wall thickness $0.8 \mathrm{~mm}$.

In determining the throughput, rates below about $5 \mathrm{ml}$ of liquid per minute may be estimated by means of the drop counter on the return end of the U-tube. Since this portion of the apparatus is thermally insulated, provision must be made for two removable plugs in the insulation layer, one in front of and one behind the drop counter, to permit observation of the falling drops. For larger rates the throughput may be estimated by opening the glass valve until no liquid returns to the rectifying section and measuring the volume of liquid collected (below $K$ ) in a given time, say $30 \mathrm{sec}$ or $1 \mathrm{~min}$. Larger rates may also be estimated by means of the drop counter inside the column by having that counter made with a bottom larger than 8 $\mathrm{mm}$ in diameter.

Acknowledgment is made of helpful suggestions received from E. O. Sperling, glassblower, and G. A. E. Rheinbold, mechanic, of the Division of Shops of this Bureau.

\section{REFERENCES}

[1] J. H. Brunn, Ind. Eng. Chem., Anal. Ed. 2, 187 (1930).

[2] J. H. Bruun, Ind. Eng. Chem., Anal. Ed. \%, 359 (1935).

[3] J. H. Bruun, and S. T. Schicktanz, BS J. Research \%, 862 (1931).

[4] H. T. Clarke, and E. J. Rahrs, Ind. Eng. Chem. 18, 1092 (1926). 
[5] C. W. Eddy, Ind. Eng. Chem., Anal. Ed. 4, 198 (1932).

[6] M. R. Fenske, The Science of Petroleum, vol. II, sec. 25, p. 1544 (Oxford University Press, London, 1938).

[7] M. R. Fenske, D. Quiggle, and C. O. Tongberg, Ind. Eng. Chem. 24, 411 (1932).

[8] K. Hickman and W. Weyerts, J. Am. Chem. Soc. 52, 4714 (1930).

[9] J. B. Hill and S. W. Ferris, Ind. Eng. Chem. 19, 379 (1927).

[10] E. B. Kester and R. Andrews, Ind. Eng. Chem., Anal. Ed. 3, 373 (1931).

[11] E. H. Leslie and J. C. Geniesse, Ind. Eng. Chem. 18, 591 (1926).

[12] R. T. Leslie and S. T. Schicktanz, BS J. Research 6, 379 (1931).

[13] A. W. T. Loveless, Ind. Eng. Chem. 18, 826 (1926).

[14] M. J. Marshall, Ind. Eng. Chem. 20, 1379 (1928).

[15] M. J. Marshall and B. P. Sutherland, Ind. Eng. Chem. 19, 735 (1927).

[16] C. H. Meyers, J. Am. Chem. Soc. 45, 2135 (1923).

[17] W. A. Peters, Jr. and T. Baker, Ind. Eng. Chem. 18, 69 (1926).

[18] S. C. Rothmann, Ind. Eng. Chem., Anal. Ed. §, 338 (1933).

[19] A. M. Schwartz and M. T. Bush, Ind. Eng. Chem., Anal. Ed. 3, 138 (1931).

[20] J. H. Simons, Ind. Eng. Chem., Anal. Ed. 10, 29 (1938).

[21] C. O. Tongberg, D. Quiggle, and M. R. Fenske, Ind. Eng. Chem. 26, 1213 (1934).

[22] E. C. Wagner and J. K. Simons, Ind. Eng. Chem. Anal. Ed. 5, 183 (1933).

Washington, August 4, 1939. 